\title{
Whirling technique for thyroid fine needle aspiration biopsy: a preliminary study of effectiveness and safety
}

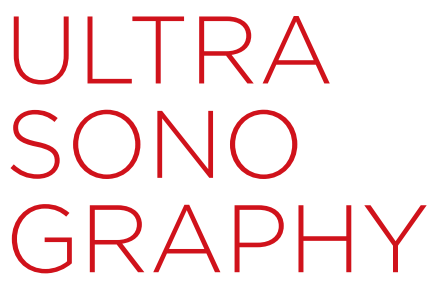

Jae Ho Shin, Seung Wan Han, Hyang Lim Lee, Yon Kwon Ihn

Department of Radiology, St. Vincent's Hospital, College of Medicine, The Catholic University of Korea, Suwon, Korea

\section{ORIGINAL ARTICLE}

https://doi.org/10.14366/usg.20031 pISSN: 2288-5919 - eISSN: 2288-5943 Ultrasonography 2021;40:147-157

Purpose: This study was aimed to compare thyroid fine needle aspiration biopsy (FNAB) techniques (conventional vs. whirling) in terms of cell harvesting ability ex vivo, the unsatisfactory rate and complication rate in vivo, and multi-operator performance in a phantom study.

Methods: In the ex vivo study, cell counts per background at $\times 100$ magnification were compared between both techniques. In the in vivo study, 70 patients who underwent whirling FNAB from July 2019 to November 2019 were retrospectively compared to 140 matched patients who underwent conventional FNAB from January 2018 to November 2019 regarding the unsatisfactory rate and complication rate. As a subgroup analysis, thyroid nodules in difficult biopsy situations (nodule diameter $<10 \mathrm{~mm}$ and location within $3 \mathrm{~mm}$ from major anatomical structures) were compared. In the phantom study, eight operators with varying experience recorded levels of dexterity and needle tip visualization, and their preferences for both techniques. Results: In the ex vivo study, cell counts were comparable between both techniques in all thyroid nodule mimickers $(80.0 \%$ vs. $87.5 \%, P=0.178)$. In the in vivo study, the unsatisfactory rate was comparable between the two groups ( $15.7 \%$ vs. $12.9 \%, P=0.859$ ). In the subgroup analysis, the whirling technique demonstrated a lower unsatisfactory rate $(5.9 \%$ vs. $24.2 \%, P=0.045)$ and a lower complication rate ( $0 \%$ vs. $6.1 \%, P=0.553)$. In the phantom study, the whirling technique demonstrated better dexterity and needle tip visualization and was preferred by all operators.

Conclusion: This newly proposed whirling technique for thyroid FNAB may be effective and safe, especially in difficult biopsy situations.

Keywords: Thyroid; Nodule; Fine needle biopsy

Received: March 2, 2020

Revised: May 6, 2020

Accepted: May 9, 2020

Correspondence to: Yon Kwon Ihn, MD, PhD, Department of Radiology, St. Vincent's Hospital, College of Medicine, The Catholic University of Korea, 93 Jungbu-daero, Paldal-gu, Suwon 16247, Korea

Tel. +82-31-249-7491

Fax. $+82-1577-8588$

E-mail: inn@catholic.ac.kr

This is an Open Access article distributed under the terms of the Creative Commons Attribution NonCommercial License (http://creativecommons.org/ licenses/by-nc/4.0/) which permits unrestricted noncommercial use, distribution, and reproduction in any medium, provided the original work is properly cited.

Copyright (C) 2021 Korean Society of Ultrasound in Medicine (KSUM)

\section{Introduction}

Thyroid nodules are common, with an incidental detection rate of $19 \%$ to $68 \%$ [1-4]. Fine needle aspiration biopsy (FNAB) is an optimal diagnostic tool for thyroid nodules because it is cost-effective, safe, and accurate [5-8]. While the Bethesda guidelines for thyroid FNAB recommend that the unsatisfactory rate on cytopathology should be approximately $10 \%$ [9], the unsatisfactory rate ranges from $0.4 \%$ to $40.7 \%$ depending on the operator's experience [10]. For that reason, recent studies have reported the utilization of first-line or second-line core needle biopsy to increase diagnostic yield [11-13]. 
The conventional to-and-fro technique for FNAB may be suboptimal for effective and safe specimen acquisition. To-andfro movement while visualizing the needle tip and simultaneously applying negative pressure can be challenging when the nodule is small, ill-defined, or located near anatomical structures like major vessels, the trachea, and the esophagus. Furthermore, poor cooperation by the patient, such as coughing, swallowing, talking, or making inappropriate jaw motion, can obscure the visualization of the needle tip to a great extent. More importantly, intranodular hemorrhage due to the repetitive to-and-fro motion combined with forceful aspiration can contaminate the specimen with blood $[2,14]$. Furthermore, failure of constant needle tip visualization during procedure can cause injuries to major vessels, the trachea, the esophagus, or nerves, which may necessitate more aggressive management than icepack application or manual compression [15].

Herein, we devised a novel whirling FNAB technique that may help harvest specimens effectively and safely by ensuring needle tip visualization, especially in difficult biopsy situations. The purpose of this study was to compare thyroid FNAB techniques (conventional to-and-fro vs. whirling) in terms of cell harvesting ability ex vivo, the unsatisfactory rate and complication rate in vivo, and multioperator performance in phantom models simulating difficult biopsy situations.

\section{Materials and Methods}

\section{Conventional FNAB Technique}

The conventional FNAB technique was performed under ultrasonography guidance (Canon Medical Systems Co., Seoul, Korea), using a 7.5-14 MHz linear probe and a 24-G needle with a 10-mL syringe in a parallel orientation [16]. The transisthmus needle approach was implemented. As the needle tip was visualized at the very surface of the thyroid, the needle was advanced slowly until the needle tip was placed at the target. The specimen was collected with six to seven to-and-fro motions for 10 seconds to induce capillary sampling [10]. In order to further facilitate capillary sampling, a slight negative pressure was created with regular aspiration of 3 $\mathrm{mL}$ during the to-and-fro motion [10]. If an insufficient amount of specimen was visualized at the needle hub, we repeated the toand-fro motion at different quadrants of the nodule by tilting the needle angle or by relocating the needle tip $[10,17]$. We released the negative pressure before withdrawing the needle to prevent needle tract seeding or hemorrhage $[10,15]$. We performed only one conventional FNAB in each session.

\section{Whirling FNAB Technique}

The whirling FNAB technique was performed under the same settings as the conventional FNAB technique. When the needle tip was visualized at the target, the operator alternately rotated the needle back and forth (i.e., made a whirling motion) with the index finger and third finger, while the thumb served as a fulcrum (Fig. 1). The fourth finger and fifth finger were placed on the syringe for additional stability during tissue sampling. The whirling motion was applied gently 10 to 15 times for 10 seconds. The application and release of a slight negative pressure, as well as the strategy for an insufficient amount of the specimen, were the same as in the conventional FNAB technique. We performed only one whirling FNAB in each session.

\section{Ex Vivo Study}

Under institutional review board (IRB) approval, an ex vivo study was conducted using commercially available orange pulp and bovine tissues, which did not include any experimentation on live animals or extraction of tissues from live animals. Orange pulp suspended in sweet jelly, bovine liver, bovine lung, and bovine muscles from the anterior part of thigh were utilized. Strain elastography was performed on each specimen to measure strain values. The orange pulp simulated a cystic thyroid nodule, while the bovine lung, bovine liver, and bovine muscle simulated solid thyroid nodules with various elasticity values. Two board-certified radiologists (the first radiologist

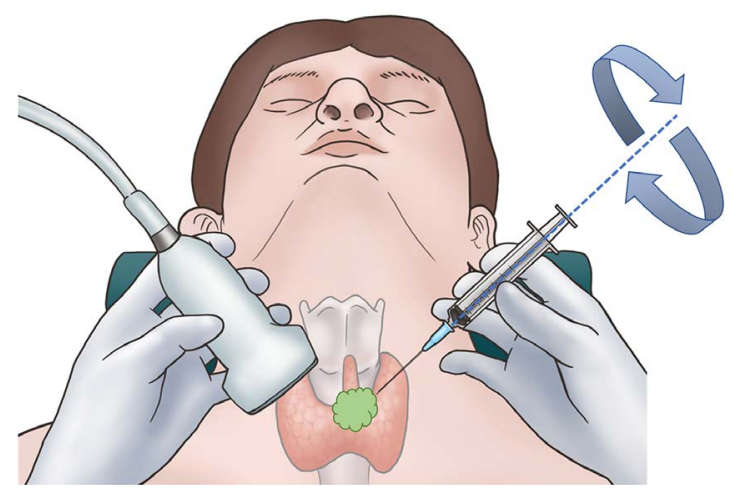

Fig. 1. Diagram of the whirling technique. When the needle tip is visualized at the target, the operator alternately rotates the needle back and forth with the index finger and the third finger, while the thumb serves as a fulcrum. The fourth finger and fifth finger are placed on the syringe for additional stability during tissue sampling. The whirling motion is performed gently 10 to 15 times for 10 seconds. In order to further facilitate capillary sampling, a slight negative pressure is created, which is released before withdrawing the needle. If an insufficient amount of specimen is visualized at the needle hub, the whirling motion can be repeated at different quadrants of the nodule. The whirling fine needle aspiration biopsy technique allows constant needle tip visualization, as the needle tip remains in the same location, while capillary sampling is enabled by rotating along the axis. 
with more than 10 years of experience in thyroid imaging, and the second radiologist with 2 years of experience in thyroid imaging and thyroid interventions) performed the FNABs. Both the whirling technique and conventional to-and-fro technique were applied twice for each thyroid nodule mimicker for less than 20 seconds to simulate in vivo FNAB. Each harvested specimen was smeared on a slide using 95\% ethyl alcohol, fixed, and stained with azure-eosinmethylene blue (Giemsa solution, Sigma-Aldrich, Seoul, Korea). To measure cell harvesting ability, cell counts per background at $\times 100$ magnification were semi-quantitatively recorded for each slide and the median values were compared (Fig. 2). Referring to the 2017 Bethesda system for cytology [18], specimens with fluid

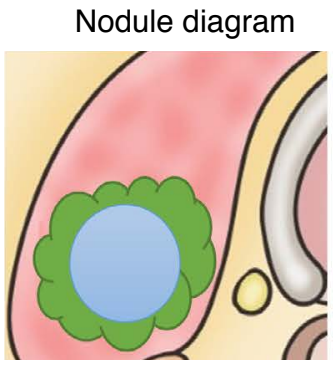

A

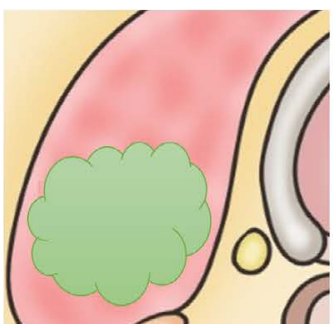

B
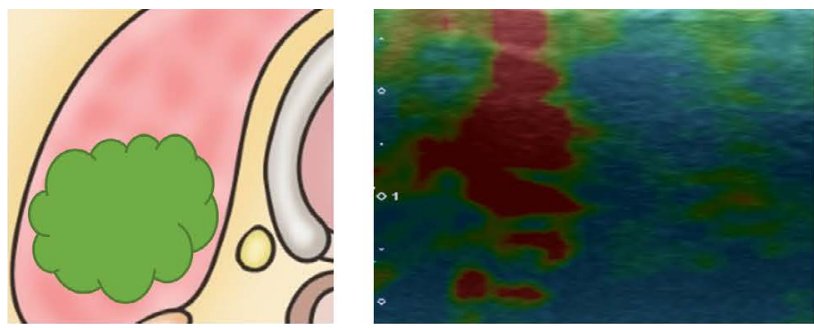

C
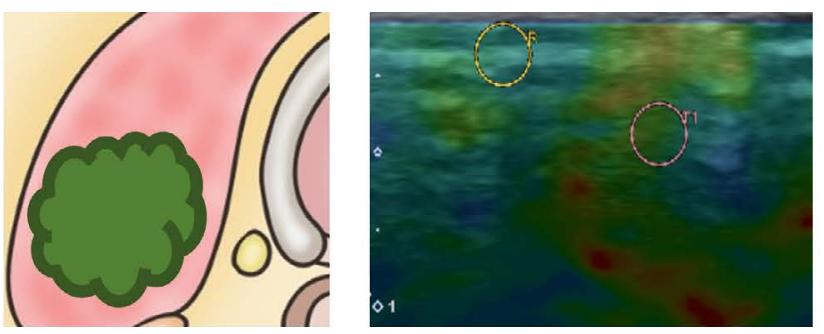

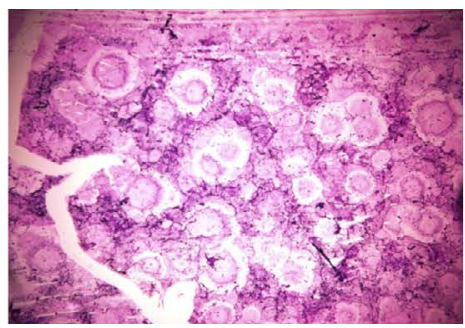

Conventional FNAB
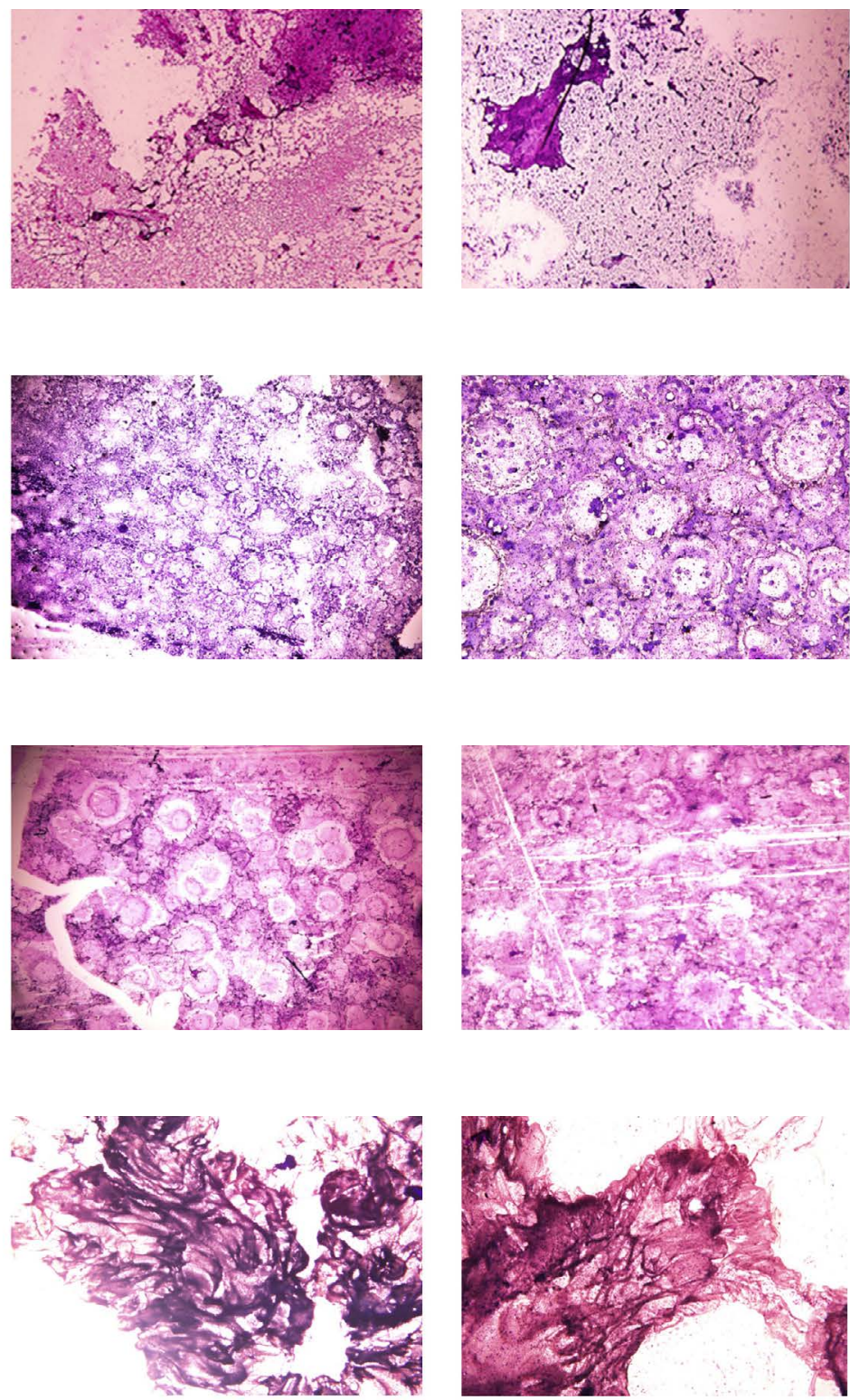

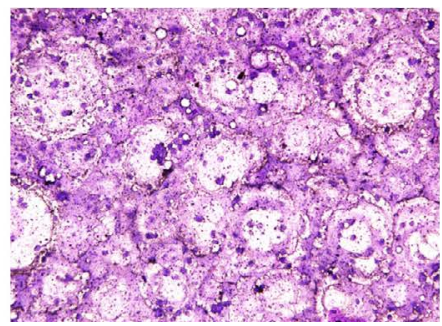

Whirling FNAB

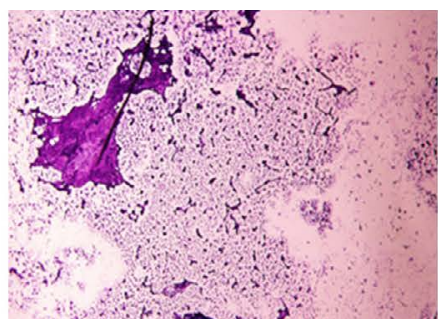

D

Fig. 2. Summary of the ex vivo study.

A. Orange pulp suspended in jelly represented a cystic nodule mimicker with high elasticity (strain value, $0.02 \%$ ). B. Bovine liver represented a solid nodule with medium elasticity (strain value, $0.3 \%$ ). C. Bovine lung represented a solid nodule with medium elasticity (strain value, $0.4 \%$ ). D. Bovine muscle represented a solid nodule with low elasticity (strain value, $8.4 \%$ ). Cell harvesting was successful using both the conventional fine needle aspiration biopsy (FNAB) and the whirling FNAB techniques (median semiquantitative cell count per background on a $\times 100$ magnification microscope field: conventional technique $[80.0 \%]$ vs. whirling technique $[87.5 \%] ; P=0.178)$. 
only, acellular specimens, blood-contaminated specimens, and thick smears were defined as unsatisfactory.

\section{In Vivo Study}

Our IRB approved the retrospective review of the medical records and images of patients who underwent thyroid FNAB at our institution from January 2018 to November 2019 with a waiver of informed consent from patients (Fig. 3).

The same two board-certified radiologists (the first radiologist with 10 years of experience in thyroid imaging, and the second radiologist with 2 years of experience in thyroid imaging and thyroid interventions) routinely classified the thyroid nodules based on ultrasonography findings according to the Korean Thyroid Imaging Reporting and Data System (K-TIRADS) as follows: category 1, no nodule; category 2, benign nodule; category 3, nodule with low suspicion; category 4, nodule with intermediate suspicion; and category 5, nodule with high suspicion of malignancy [19]. Our institutional indications for thyroid FNAB were in compliance with the revised Korean Society of Thyroid Radiology guideline published in 2016 [3,19]. Any solid hypoechoic nodules greater than $10 \mathrm{~mm}$ with suspicious features such as microcalcification, non-parallel orientation, and spiculated or microlobulated margins were indications for FNAB. Based on the discretion of the referring physicians and shared decision-making, any solid hypoechoic nodules less than $10 \mathrm{~mm}$ with suspicious ultrasonographic features with or without a family history of thyroid cancer, growth tendency, and radiation history were indications for FNAB. Specimens were either prepared on a slide using $95 \%$ ethyl alcohol or in alcohol-based solutions for liquid-based cytology by a dedicated technician in the radiology department. According to the Bethesda system [18], specimens were interpreted by one of five boardcertified pathologists with at least 2 years of experience in thyroid cytopathology.

The novel whirling FNAB technique was performed in 70 randomly selected patients (i.e., the study group) from July 2019 to November 2019 by the second board-certified radiologist with 2 years of experience in thyroid imaging and interventions. For the control group, 1,36 patients were enrolled who underwent conventional thyroid FNAB from January 2018 to November 2019 performed by one of the three radiologists (the same two radiologists who performed the ex-vivo FNABs and another radiologist with 10 years of experience in thyroid imaging). A further selection was made by $1: 2$ nearest matching to the study group based on the maximal nodule diameter and the internal content of the nodule. The FNAB for the control group was performed by one of two board-certified radiologists. Age, sex, nodule content, calcification, intranodular vascularity, nodule diameter, K-TIRADS category, specimen preparation, pathologic results, the unsatisfactory rate, and the complication rate were retrospectively reviewed for the study group and control group. In accordance with the Society of Interventional Radiology and other studies, major complications were defined as follows: permanent adverse sequelae, complications requiring surgical intervention, and/or complications requiring hospitalization [20-22]. We evaluated the effectiveness of each FNAB technique by assessing the unsatisfactory rate and safety by assessing the complication rate.

We also evaluated how these techniques performed in difficult biopsy situations in terms of the unsatisfactory rate and complication rate. We defined and subcategorized difficult biopsy situations for each technique as follows: a thyroid nodule with a maximal

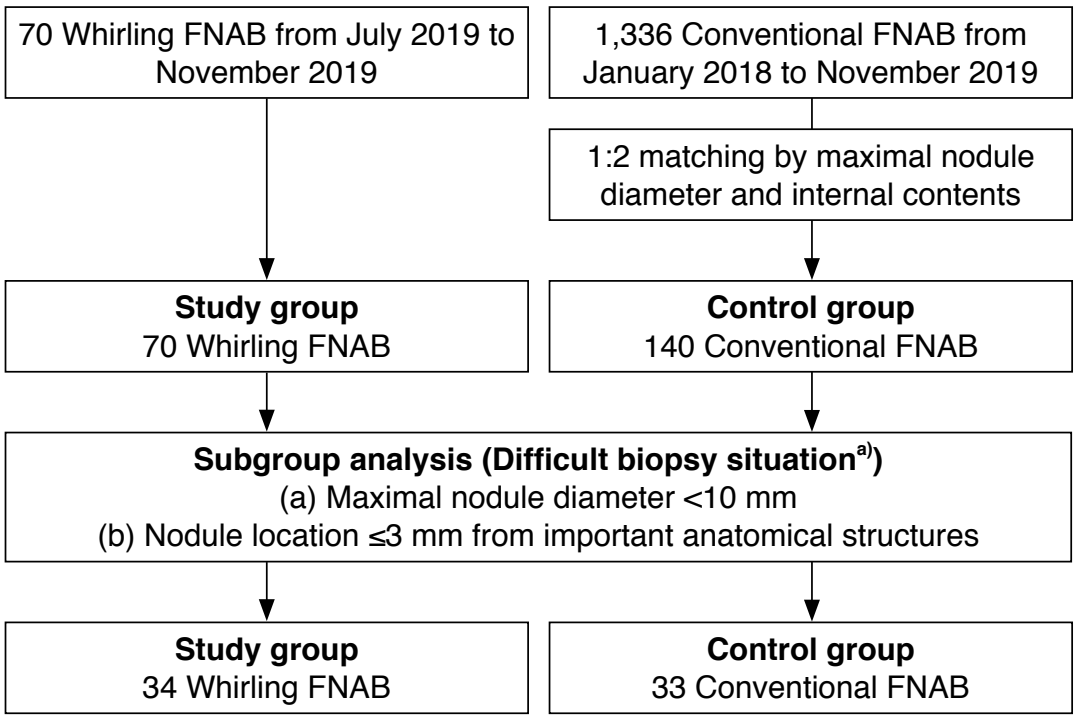

Fig. 3. Patient selection for the in vivo study and subgroup analysis. Seventy thyroid nodules that were biopsied with the whirling technique from July 2019 to November 2019 was included in the study group. For the control group, 140 thyroid nodules that were biopsied with the conventional technique from January 2018 to November 2019 were matched at a ratio of $1: 2$ based on the maximal nodule diameter and the internal content of the nodules. A subgroup analysis of difficult biopsy situations was done for 34 nodules in the study group and 33 nodules in the control group. FNAB, fine needle aspiration biopsy. ${ }^{\text {a) }}$ Difficult biopsy situations (nodule diameter $<10 \mathrm{~mm}$ and location within $3 \mathrm{~mm}$ from major anatomical structures). 
diameter less than $10 \mathrm{~mm}$ and located within $3 \mathrm{~mm}$ of anatomical structures such as the common carotid artery, esophagus, trachea, and perithyroidal vessels (Fig. 4). Any thyroid nodules larger than 10 $\mathrm{mm}$ and located more than $3 \mathrm{~mm}$ away from anatomical structures were excluded.
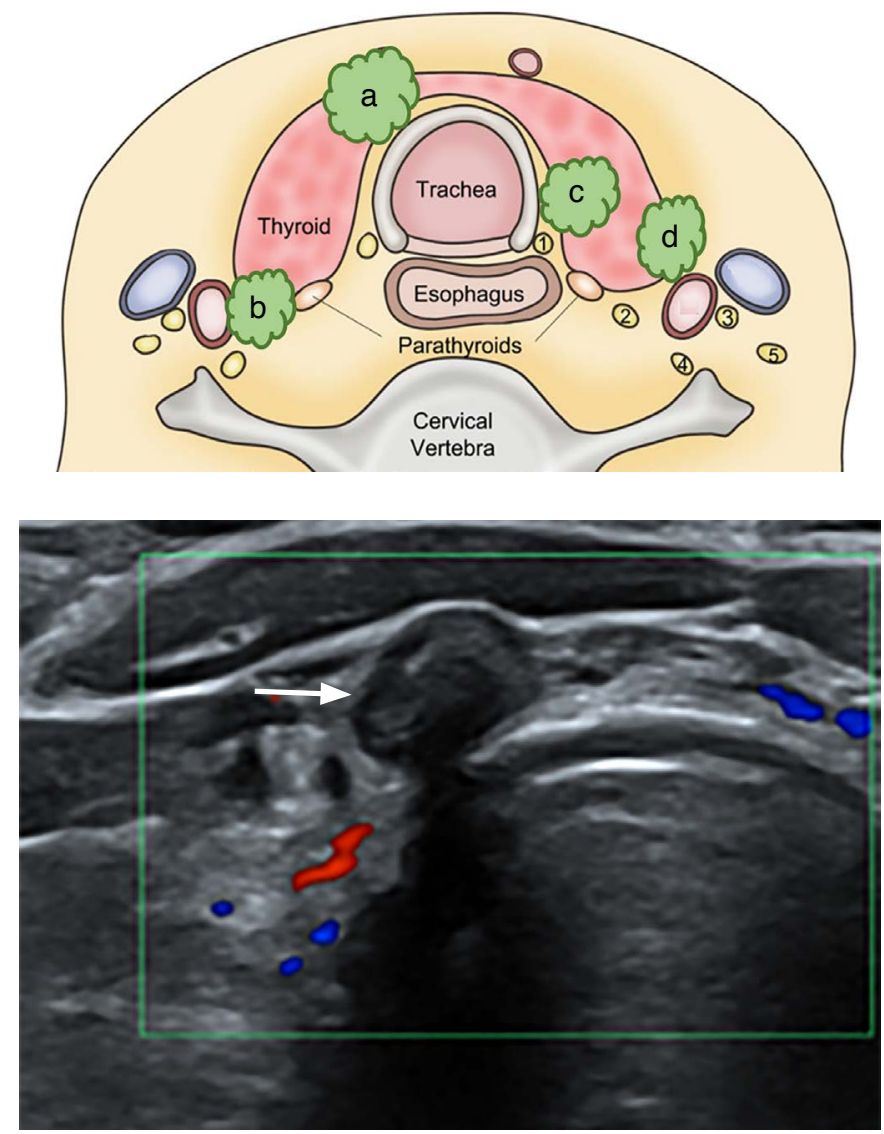

a

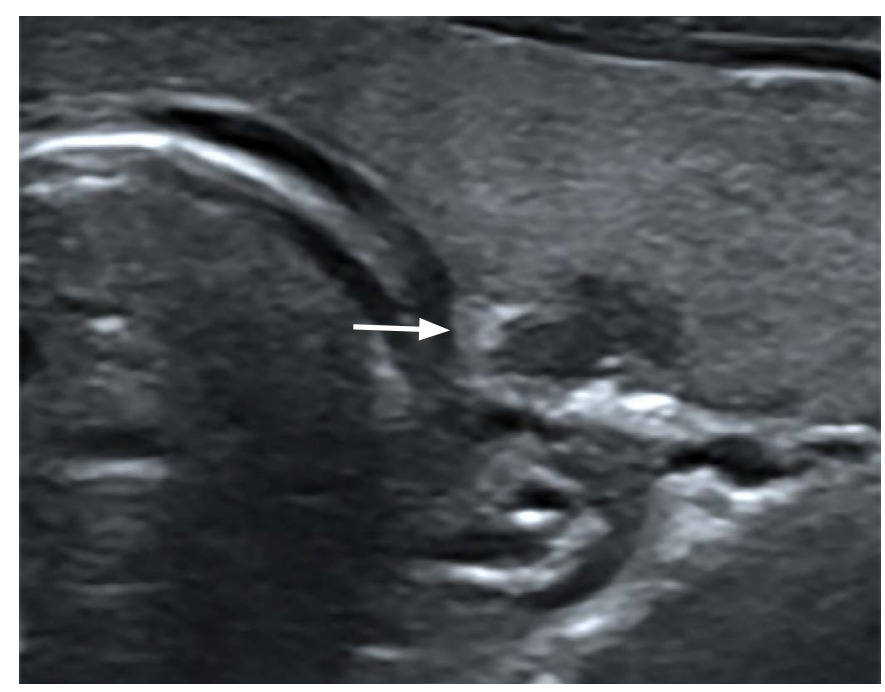

C

\section{Phantom Study}

The phantom study was designed to simulate difficult biopsy situations in real clinical settings. Thyroid phantom models were created utilizing commercially available tofu (bean curd), commercially available straws, and 24-gauge needles, as proposed

Fig. 4. Definition of a difficult biopsy situation.

Thyroid nodules (arrows) with a maximal diameter less than $10 \mathrm{~mm}$, and a location within $3 \mathrm{~mm}$ of major anatomical structures, such as the trachea (a), the right common carotid artery (CCA) (b), the esophagus (c), the left CCA (d), and prominent perithyroidal vessels (not shown), were defined as difficult biopsy situations.

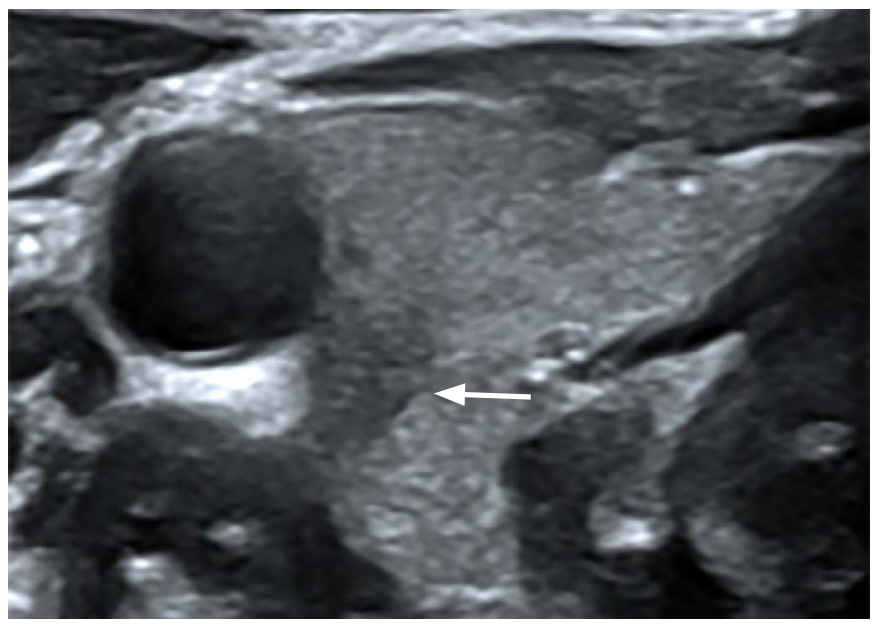

b

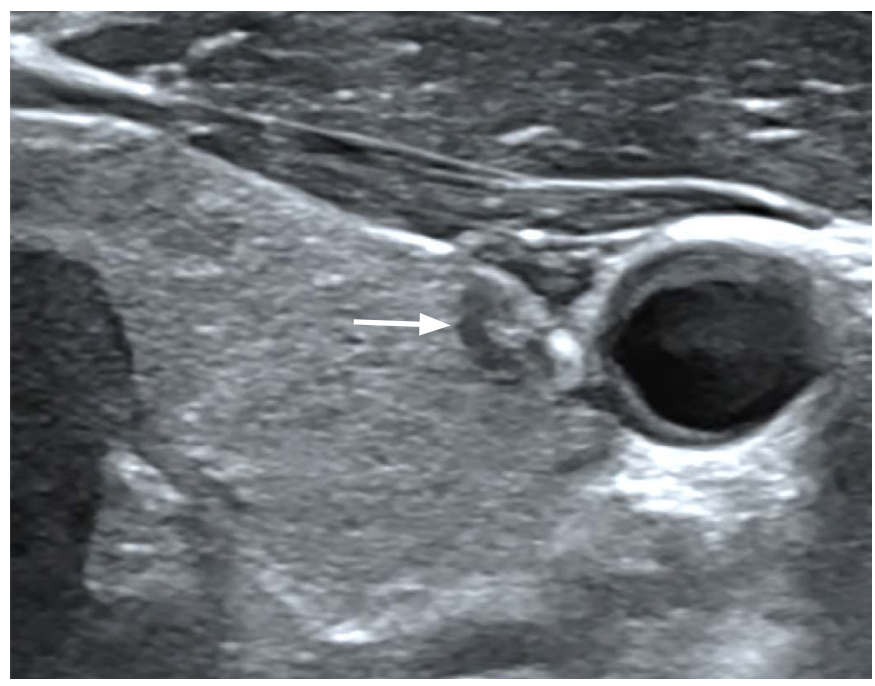

d 
by Zhang et al. [23]. An empty 2-mL syringe was inserted at the midline of the tofu to simulate the phantom's trachea, and small- and large-caliber straws filled with ultrasonography gel were inserted at each edge of the tofu to simulate common carotid arteries and internal jugular veins, respectively. Manual pumping was applied to $30-\mathrm{mL}$ syringes filled with water and connected to the phantom arteries by a study coordinator to mimic arterial pulsations. Phantom thyroid nodules smaller than $10 \mathrm{~mm}$ were simulated with 24-gauge needles and inserted at locations within $3 \mathrm{~mm}$ of the phantom trachea and phantom vessels (Fig. 5).

Eight operators with various levels of experience in thyroid FNAB (novice operators, two second-year radiology residents and two third-year radiology residents; experienced operators, two fourthyear radiology residents and two board-certified radiologists) participated in the phantom study. A study coordinator instructed the operators regarding the techniques prior to the experimental session, and a practice session was provided to the operators over the course of a week. Each operator performed both techniques for two phantom nodules. The study coordinator judged the adequacy of each FNAB by each operator using the following criteria: (1) correct targeting, (2), correct needle trajectory, (3) avoidance of phantom trachea and vessels, and (4) correct to-and-fro movement or whirling motion. After the experimental session, operators responded to questionnaires evaluating their level of dexterity, level of needle tip

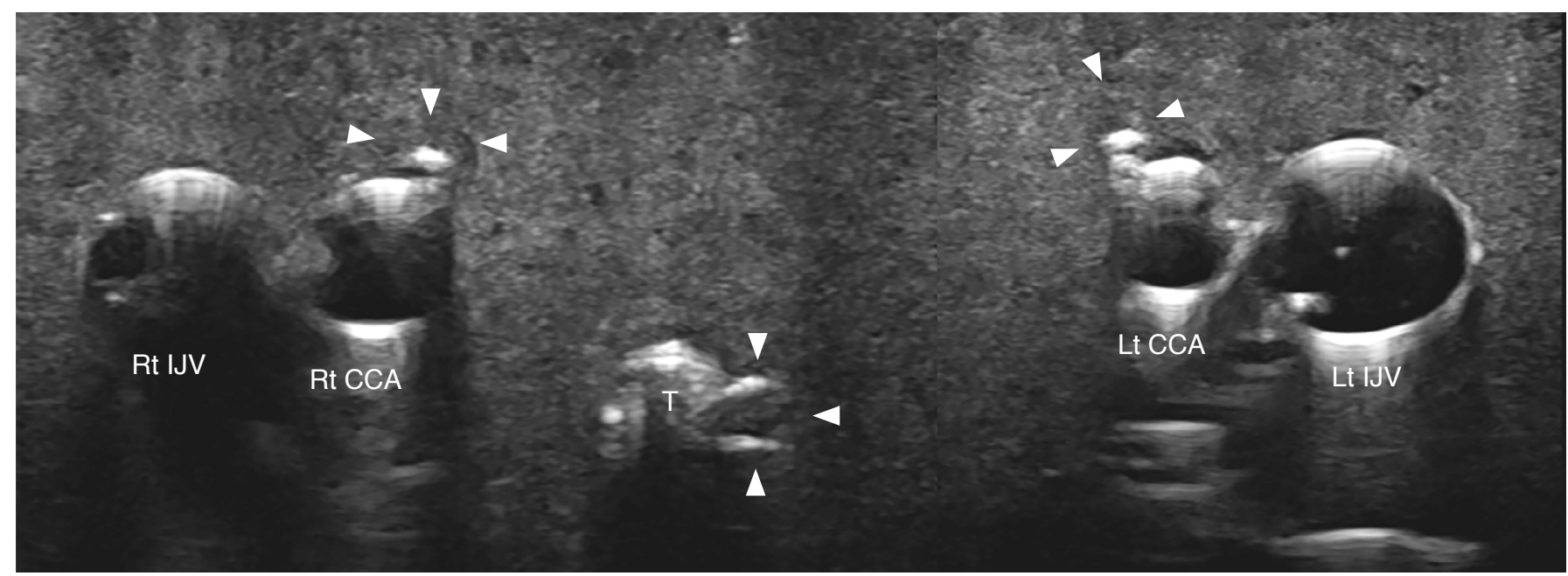

A

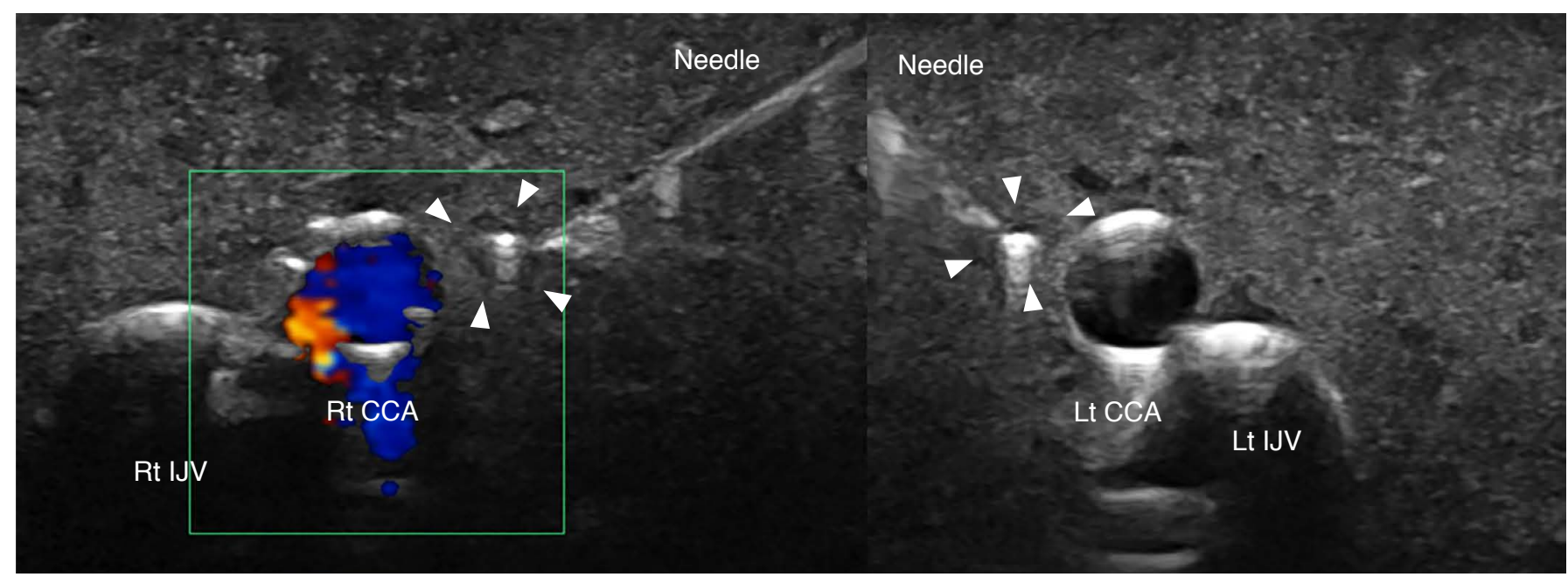

B

Fig. 5. Phantom models simulating difficult biopsy situations.

A. Thyroid phantom models with a phantom trachea (T), phantom vessels (common carotid artery [CCA], and internal jugular vein [IJV]), and phantom nodules (arrowheads) were created. B. Eight operators with varying experience with thyroid fine needle aspiration biopsy performed both techniques (conventional and whirling) and recorded their level of dexterity, level of needle tip visualization, and preference. 
visualization, and preference using a 5-point Likert scale (1, strongly disagree; 2, disagree; 3, neither agree nor disagree; 4, agree; 5 , strongly agree).

\section{Statistical Analysis}

For the ex vivo study, cell harvesting abilities were compared between the two techniques using the Mann-Whitney $U$ test. For the in vivo study, the control group was selected by using nearest matching to the study group with a 1:2 ratio based on the maximal diameter and internal content of nodules. The Student t-test or the Mann-Whitney $U$ test was performed to compare continuous variables, and the chi-square test was used to compare categorical variables in the ex vivo study and phantom study. The R statistical program (version 3.6.1, The R Foundation for Statistical Computing, Vienna, Austria) was used for the analysis. A two-sided P-value less than 0.05 was considered to indicate statistical significance.

\section{Results}

\section{Ex Vivo Study}

The strain values measured for the orange pulp, bovine liver, bovine lung, and bovine muscle were $0.02 \%, 0.3 \%, 0.4 \%$, and $8.4 \%$, respectively. Thus, the orange pulp, bovine liver or lung, and bovine muscle represented tissue with high, medium, and low elasticity, respectively, and were considered to mimic thyroid nodules with various elasticity values (Fig. 4). The cell harvesting ability was comparable between conventional FNAB and whirling FNAB (median semiquantitative cell counts per background on $\times 100$ magnification microscope field: conventional technique, $80.0 \%$ vs. whirling technique, $87.5 \%, P=0.178$ ). No unsatisfactory specimens were obtained using either technique.

\section{In Vivo Study}

The mean patient age $(58.5 \pm 11.8$ years vs. $57.6 \pm 13.4$ years, $P=0.981)$ and the proportion of women $(87.1 \%$ vs. $87.1 \%$, $\mathrm{P}=0.990$ ) were comparable between the control group and the study group (Table 1). The nodule content (solid, predominantly solid, predominantly cystic) was comparable between both groups $(P=0.434)$. Calcification (none, microcalcification, rim calcification, or macrocalcification) was also comparable between both groups ( $P=0.572$ ). Additionally, the Doppler signals representing intranodular hypervascularity (none or minimal, perinodular hypervascularity, and hypervascularity) were comparable between both groups $(P=0.413)$. The mean nodule diameter was smaller in the study group than in the control group (anterior to posterior, $9.2 \pm 5.2 \mathrm{~mm}$ vs. $8.8 \pm 6.0 \mathrm{~mm}$; width, $12.2 \pm 7.6 \mathrm{~mm}$ vs. $7.5 \pm 5.0$ $\mathrm{mm}$; caudal to cranial, $15.5 \pm 9.8 \mathrm{~mm}$ vs. $8.6 \pm 6.9 \mathrm{~mm} ; \mathrm{P}<0.001$ for both groups). The K-TIRADS category ( $\mathrm{P}=0.054)$ and the method of specimen preparation were comparable between the techniques $(P=0.144)$. The Bethesda category ( $P=0.859$ ) was also comparable between the techniques. The unsatisfactory rate was $15.7 \%$ and $12.9 \%$ in the control group and study group, respectively $(P=0.859)$. Two minor complications occurred in the control group: puncture at

Table 1. Summary of the in vivo study

\begin{tabular}{|c|c|c|c|}
\hline & $\begin{array}{c}\text { Conventional } \\
\text { technique (control } \\
\text { group, } n=140 \text { ) }\end{array}$ & $\begin{array}{c}\text { Whirling } \\
\text { technique (study } \\
\text { group, } \mathrm{n}=70 \text { ) }\end{array}$ & P-value \\
\hline Age (y) & $58.5 \pm 11.8$ & $57.6 \pm 13.4$ & 0.981 \\
\hline Female sex & $122(87.1)$ & $61(87.1)$ & 0.990 \\
\hline Nodule content & & & 0.434 \\
\hline Solid & $113(80.7)$ & $52(74.3)$ & \\
\hline Predominantly solid & $24(17.1)$ & $15(21.4)$ & \\
\hline Predominantly cystic & $3(2.1)$ & $3(4.3)$ & \\
\hline Calcification & & & 0.572 \\
\hline None & $111(79.3)$ & $53(75.7)$ & \\
\hline Microcalcification & $15(10.7)$ & $11(15.7)$ & \\
\hline $\begin{array}{l}\text { Macro- or rim } \\
\text { calcification }\end{array}$ & $14(10.0)$ & $6(8.6)$ & \\
\hline Vascularity & & & 0.413 \\
\hline $\begin{array}{l}\text { None or minimal } \\
\text { vascularity }\end{array}$ & $103(73.6)$ & $53(75.7)$ & \\
\hline $\begin{array}{l}\text { Intranodular } \\
\text { hypervascularity }\end{array}$ & $13(9.3)$ & $3(4.3)$ & \\
\hline $\begin{array}{l}\text { Perinodular } \\
\text { hypervascularity }\end{array}$ & $24(17.1)$ & $14(20.0)$ & \\
\hline \multicolumn{4}{|l|}{ Nodule diameter (mm) } \\
\hline Anterior to posterior & $9.2 \pm 5.2$ & $8.8 \pm 6.0$ & $<0.001$ \\
\hline Width & $12.2 \pm 7.6$ & $7.5 \pm 5.0$ & $<0.001$ \\
\hline Caudal to cranial & $15.5 \pm 9.8$ & $8.6 \pm 6.9$ & $<0.001$ \\
\hline K-TIRADS category & & & 0.054 \\
\hline 2 (benign) & $4(2.9)$ & 0 & \\
\hline 3 (low suspicion) & $58(41.4)$ & $20(28.6)$ & \\
\hline $\begin{array}{l}4 \text { (intermediate } \\
\text { suspicion) }\end{array}$ & $54(38.6)$ & $40(57.1)$ & \\
\hline 5 (high suspicion) & $24(17.1)$ & $10(14.3)$ & \\
\hline Specimen preparation & & & 0.144 \\
\hline Slide smear & $58(41.4)$ & $21(30.0)$ & \\
\hline Liquid & $82(58.6)$ & $49(70.0)$ & \\
\hline Bethesda category & & & 0.859 \\
\hline । & $22(15.7)$ & $9(12.9)$ & \\
\hline$\|$ & $87(62.1)$ & $43(61.4)$ & \\
\hline III & $15(10.7)$ & $10(14.3)$ & \\
\hline VorVI & $16(11.4)$ & $8(11.4)$ & \\
\hline
\end{tabular}

Values are presented as mean \pm standard deviation or number of nodules (\%). K-TIRADS, Korean Thyroid Imaging Reporting and Data System. 
the right common carotid artery and subcutaneous hematoma at the puncture site (1.4\% vs. $0 \%, P=0.553)$ (Table 1$)$. These complications were managed with manual compression and application of an icebag. No hospitalization nor surgical interventions were required for these two patients and no permanent adverse sequelae were observed.

When we conducted a subanalysis of difficult biopsy situations (thyroid nodule $<10 \mathrm{~mm}$ and located within $3 \mathrm{~mm}$ of major anatomical structures), 33 thyroid nodules were considered to represent difficult situations for the to-and-fro conventional technique and 34 thyroid nodules were considered to represent difficult situations for the whirling technique. Within the subgroup of difficult biopsy situations, the conventional technique group had eight unsatisfactory cases $(24.2 \%)$ and two cases of complications (6.1\%), while the whirling technique group had only two unsatisfactory cases (5.9\%) and 0 complications. In difficult biopsy situations, the whirling technique demonstrated a lower unsatisfactory rate than the conventional technique (24.2\% vs. $5.9 \%$, $\mathrm{P}=0.045$ ). Although two cases of complications (common carotid artery puncture and subcutaneous hematoma) occurred in the conventional group, the difference in the complication rate between the groups was not statistically significant $(6.1 \%$ vs. $0 \%, \mathrm{P}=0.239)$.

As summarized in Table 2, within the subgroup of non-difficult biopsy situations, the conventional technique group had 14 unsatisfactory cases $(13.1 \%)$ and no complications, while the whirling technique group had seven unsatisfactory cases (19.4\%) and no complications. In non-difficult biopsy situations, the whirling technique and the conventional technique were comparable in terms of the unsatisfactory rate $(13.1 \%$ vs. $19.4 \%, P=0.351)$ (Table 2$)$.

\section{Phantom Study}

The adequacy criteria were satisfied for both techniques by all operators. Although novice operators required additional instructions and practice time, they successfully performed both techniques without any failed attempts.

As summarized in Table 3, all operators reported that the whirling technique was easier to perform, easier to control, easier for visualization of the needle tip, and preferable to the conventional technique in simulated difficult biopsy situations. The median scores for the level of dexterity were 1.5 (interquartile range [IQR], 1 to 2) for the conventional technique and 4 (IQR, 4 to 4.25$)$ for the whirling technique $(P<0.001)$. The median scores for the level of needle tip visualization were 2 (IQR, 2 to 3 ) for the conventional technique and 4 (IQR, 3.75 to 4.25$)$ for the whirling technique $(P=0.002)$. The median score for preference of the whirling technique was 4 (IQR, 4 to 4.25) (Table 3).

There were no significant differences in the median scores between novice operators and experienced operators for both techniques: level of dexterity for the conventional technique, 1 (IQR, 1 to 1.25 ) vs. 2 (IQR, 1.75 to 2.25$), P=0.065$; level of dexterity for

Table 2. Comparison of the unsatisfactory rate and complication rate in vivo

\begin{tabular}{|c|c|c|c|}
\hline & $\begin{array}{c}\text { Conventional } \\
\text { technique (control } \\
\text { group, } n=140 \text { ) }\end{array}$ & $\begin{array}{l}\text { Whirling technique } \\
\text { (study group, } \\
n=70)\end{array}$ & P-value \\
\hline \multicolumn{4}{|l|}{ Unsatisfactory rate } \\
\hline $\begin{array}{l}\text { Difficult biopsy } \\
\text { situation }^{\text {a) }}\end{array}$ & 8 of $33(24.2)$ & 2 of $34(5.9)$ & 0.045 \\
\hline $\begin{array}{l}\text { Non-difficult biopsy } \\
\text { situation }\end{array}$ & 14 of 107 (13.1) & 7 of $36(19.4)$ & 0.351 \\
\hline Total & $22(15.7)$ & $9(12.9)$ & 0.859 \\
\hline \multicolumn{4}{|l|}{ Complication rate } \\
\hline $\begin{array}{l}\text { Difficult biopsy } \\
\text { situation }^{\text {a) }}\end{array}$ & 2 of $33(6.1)$ & 0 of 34 & 0.239 \\
\hline $\begin{array}{l}\text { Non-difficult biopsy } \\
\text { situation }\end{array}$ & 0 of 107 & 0 of 36 & N/A \\
\hline Total & $2(1.4)$ & 0 & 0.565 \\
\hline
\end{tabular}

Table 3. Multi-operator performance in the phantom study

Questionnaire
$\begin{aligned} & \text { (IQR) } \\ & \text { Level of dexterity }\end{aligned}$
It is easy and simple to perform the
conventional technique in simulated difficult
biopsy situations. ${ }^{\text {b) }}$
It is easy and simple to perform the whirling
technique in simulated difficult biopsy
situations.
Level of needle tip visualization
Most of the time, I can clearly visualize the
needle tip using the conventional technique in
simulated difficult biopsy situations.
Most of the time, I can clearly visualize the
needle tip using the whirling technique in
simulated difficult biopsy situations.
Preference
I would prefer utilizing the whirling technique
in real clinical settings, especially in difficult
biopsy situations.


the whirling technique: 4 (IQR, 3.75 to 4.25$)$ vs. 4 (IQR, 4 to 4.25 ), $P=0.574$; level of needle tip visualization for the conventional technique: 2 (IQR, 2 to 2.25 ) vs. 2.5 (IQR, 1.75 to 3), P=0.878; level of needle tip visualization for the whirling technique: 4 (IQR, 3.75 to 4.25$)$ vs. 4 (IQR, 3.75 to 4.25), $P>0.99$; and preference for the whirling technique: 4 (IQR, 4 to 4$)$ vs. 4.5 (IQR, 4 to 5), $\mathrm{P}=0.105$.

\section{Discussion}

Our study results demonstrate that the novel whirling technique is feasible and may be effective and safe for thyroid FNAB. The ex vivo comparison showed that cell harvesting was successful using both techniques for all thyroid nodule mimickers. The in vivo study showed that both techniques demonstrated acceptable unsatisfactory rates, near 10\%, as recommended by the Bethesda guidelines [9]. In difficult biopsy situations, the whirling technique demonstrated better performance than the to-and-fro conventional FNAB technique, with a lower unsatisfactory rate and lower complication incidence. In the phantom study, despite differences in operators' FNAB experience levels, it was found that the whirling technique might be easier to perform, easier to visualize (and easier to control), and more preferable than the conventional technique in simulated difficult biopsy situations.

Several previous studies have investigated the optimal techniques for thyroid FNAB. Titton et al. [24] and Oertel [25] recommended that applying negative pressure is not necessary unless capillary sampling is not spontaneously attained. This "combined method" involving negative pressure was reported to result in the harvest of sufficient specimens and a reduction of procedure-related complications [10]. Another study showed that FNAB could even be performed without applying negative pressure [26]. While both techniques used in our study were based on the combined method, the results of our study expand prior knowledge by showing that the novel whirling technique may be comparably effective and safe to the conventional to-and-fro technique. Furthermore, in difficult biopsy situations, the whirling technique may be more effective and safer than the conventional technique.

As assessed in the phantom study, the whirling technique enables constant needle tip visualization by fixing the needle tip in the same location. This constant needle tip visualization provides better control of the needle, which can reduce the unsatisfactory rate and the complication rate. In contrast, the conventional technique requires repeated advancement and retrieval of the needle along the axis, making constant visualization of the needle tip challenging. Therefore, the safety margin between a thyroid nodule and adjacent major anatomical structures is smaller in the conventional technique than in the whirling technique. Although the complication rate did not show a significant difference between the two techniques, and the two complications might have caused by the needle puncture rather than needle motion, the whirling technique may be preferable to prevent further complications in difficult biopsy situations, especially for novice operators.

We speculate that the driving biomechanical force for capillary sampling in the whirling technique is the outward force (i.e., the "centrifugal force") created by the rotating motion along the axis and the pressure gradient created by gentle aspiration. The centrifugal force is the force vector perpendicular to the axis of rotating motion exerted on the thyroid nodule that pulls tissue, fluid, and cells into the syringe. A recent article demonstrated that the centrifugal force is important in pulling on the dense solidliquid phase field in a rotating channel [27], which is analogous to the thyroid nodule tissue pulled into the syringe during whirling FNAB. The article also showed that the centrifugal force depends on both the angular rotation speed and the concentration gradient across the channel. Therefore, proper execution of the rapid whirling motion may be essential for the whirling FNAB technique.

Our study has several limitations. First, the strain values measured in ex vivo experiments not be precisely the same as those measured in human thyroid nodules. However, we tried to implement the novel technique in thyroid nodule mimickers with various elasticities to represent various thyroid nodule contents in humans. Second, as the in vivo study only included a small number of predominantly cystic nodules, the effectiveness and safety of the whirling FNAB technique may be uncertain for predominantly cystic nodules. Nonetheless, the results using orange pulp in the ex vivo experiment may have implications for predominantly cystic nodules. Third, the whirling technique cannot be generalized to other operators since only one operator performed it in vivo. However, as the phantom study demonstrated, the whirling technique might be easy to learn and easy to perform, even for novice operators. Further studies measuring the needle tip visualization score and recruiting more operators with various levels of experience are warranted to strengthen the results of our in vivo study and phantom study. Lastly, due to the small sample sizes in the in vivo and ex vivo studies, there may have been selection bias in our study, and the subcategorization resulted in a much higher number of difficult situations in the whirling FNAB group. For the same reason, the unsatisfactory FNAB rate appeared higher (19.4\%) in non-difficult biopsy situations for the whirling technique, although this difference was statistically insignificant compared to the conventional technique (15.7\% vs. $19.4 \%$, $\mathrm{P}=0.351$ ). Nevertheless, we demonstrated that the whirling FNAB technique can be useful in difficult biopsy situations and that it may be a potential alternative technique when the conventional to-andfro technique seems suboptimal. In order to further strengthen the 
evidence on the effectiveness and safety of the whirling technique, a prospective study with a large sample size, preferably a multi-center study, is necessary.

In the ex vivo study, both techniques demonstrated comparable and sufficient cell harvesting abilities. In the in vivo study, both techniques demonstrated comparable unsatisfactory and complication rates. In the subgroup analysis of difficult biopsy situations, the whirling technique performed better and had a lower unsatisfactory rate. In a phantom study, the whirling technique showed better dexterity and needle tip visualization, and was preferred to the conventional technique by all operators. The newly proposed whirling technique for thyroid FNAB may be effective and safe, especially in difficult biopsy situations, and it can be an alternative to the conventional to-and-fro technique.

ORCID: Jae Ho Shin: https://orcid.org/0000-0001-5922-5720; Seung Wan Han: https://orcid.org/0000-0001-5704-5507; Hyang Lim Lee: https://orcid.org/00000002-7281-5300; Yon Kwon Ihn: https://orcid.org/0000-0002-3770-308X

\section{Author Contributions}

Conceptualization: Shin JH. Data acquisition: Shin JH, Han SW, Lee HL, Ihn YK. Data analysis or interpretation: Shin JH, Han SW, Lee $\mathrm{HL}$, Ihn YK. Drafting of the manuscript: Shin JH. Critical revision of the manuscript: Shin JH, Ihn YK. Approval of the final version of the manuscript: all authors.

\section{Conflict of Interest}

No potential conflict of interest relevant to this article was reported.

\section{References}

1. Guth S, Theune U, Aberle J, Galach A, Bamberger CM. Very high prevalence of thyroid nodules detected by high frequency $(13 \mathrm{MHz})$ ultrasound examination. Eur J Clin Invest 2009;39:699-706.

2. Yi KH. The revised 2016 Korean Thyroid Association guidelines for thyroid nodules and cancers: differences from the 2015 American Thyroid Association guidelines. Endocrinol Metab (Seoul) 2016:31:373-378.

3. Moon WJ, Baek JH, Jung SL, Kim DW, Kim EK, Kim JY, et al. Ultrasonography and the ultrasound-based management of thyroid nodules: consensus statement and recommendations. Korean J Radiol 2011:12:1-14.

4. Ramundo V, Lamartina L, Falcone R, Ciotti L, Lomonaco C, Biffoni M, et al. Is thyroid nodule location associated with malignancy risk? Ultrasonography 2019;38:231-235.

5. Wang C, Vickery AL Jr, Maloof F. Needle biopsy of the thyroid. Surg Gynecol Obstet 1976;143:365-368.
6. Baek JH. Current status of core needle biopsy of the thyroid. Ultrasonography 2017;36:83-85.

7. Novoa E, Gurtler N, Arnoux A, Kraft M. Role of ultrasound-guided core-needle biopsy in the assessment of head and neck lesions: a meta-analysis and systematic review of the literature. Head Neck 2012;34:1497-1503.

8. Nam-Goong IS, Kim HY, Gong G, Lee HK, Hong SJ, Kim WB, et al. Ultrasonography-guided fine-needle aspiration of thyroid incidentaloma: correlation with pathological findings. Clin Endocrinol (Oxf) 2004;60:21-28.

9. Pusztaszeri M, Rossi ED, Auger M, Baloch Z, Bishop J, Bongiovanni M, et al. The Bethesda System for Reporting Thyroid Cytopathology: proposed modifications and updates for the second edition from an international panel. Acta Cytol 2016;60:399-405.

10. Lee YH, Baek JH, Jung SL, Kwak JY, Kim JH, Shin JH, et al. Ultrasoundguided fine needle aspiration of thyroid nodules: a consensus statement by the Korean Society of Thyroid Radiology. Korean I Radiol 2015;16:391-401.

11. Son HM, Kim JH, Kim SC, Yoo RE, Bae JM, Seo H, et al. Distribution and malignancy risk of six categories of the pathology reporting system for thyroid core-needle biopsy in 1,216 consecutive thyroid nodules. Ultrasonography 2020;39:159-165.

12. Trimboli P, Giovanella L. Reliability of core needle biopsy as a second-line procedure in thyroid nodules with an indeterminate fine-needle aspiration report: a systematic review and metaanalysis. Ultrasonography 2018;37:121-128.

13. Hong MJ, Na DG, Kim SJ, Kim DS. Role of core needle biopsy as a first-line diagnostic tool for thyroid nodules: a retrospective cohort study. Ultrasonography 2018;37:244-253.

14. Braga M, Cavalcanti TC, Collaco LM, Graf H. Efficacy of ultrasoundguided fine-needle aspiration biopsy in the diagnosis of complex thyroid nodules. J Clin Endocrinol Metab 2001;86:4089-4091.

15. Polyzos SA, Anastasilakis AD. Clinical complications following thyroid fine-needle biopsy: a systematic review. Clin Endocrinol (Oxf) 2009:71:157-165.

16. Degirmenci B, Haktanir A, Albayrak R, Acar M, Sahin DA, Sahin O, et al. Sonographically guided fine-needle biopsy of thyroid nodules: the effects of nodule characteristics, sampling technique, and needle size on the adequacy of cytological material. Clin Radiol 2007;62:798-803.

17. Pitman MB, Abele J, Ali SZ, Duick D, Elsheikh TM, Jeffrey RB, et al. Techniques for thyroid FNA: a synopsis of the National Cancer Institute Thyroid Fine-Needle Aspiration State of the Science Conference. Diagn Cytopathol 2008;36:407-424.

18. Cibas ES, Ali SZ. The 2017 Bethesda System for Reporting Thyroid Cytopathology. Thyroid 2017;27:1341-1346.

19. Shin JH, Baek JH, Chung J, Ha EJ, Kim JH, Lee YH, et al Ultrasonography diagnosis and imaging-based management of thyroid nodules: revised Korean Society of Thyroid Radiology 
consensus statement and recommendations. Korean J Radiol 2016;17:370-395.

20. Sacks D, McClenny TE, Cardella JF, Lewis CA. Society of Interventional Radiology clinical practice guidelines. J Vasc Interv Radiol 2003;14(9 Pt 2):S199-S202.

21. Ha EJ, Suh CH, Baek JH. Complications following ultrasound-guided core needle biopsy of thyroid nodules: a systematic review and meta-analysis. Eur Radiol 2018;28:3848-3860.

22. Saad WE, Wallace MJ, Wojak JC, Kundu S, Cardella JF. Quality improvement guidelines for percutaneous transhepatic cholangiography, biliary drainage, and percutaneous cholecystostomy. J Vasc Interv Radiol 2010;21:789-795.

23. Zhang YF, Li H, Wang XM. Technical report: a cost-effective, easily available Tofu model for training residents in ultrasound-guided fine needle thyroid nodule targeting punctures. Korean J Radiol
2019;20:166-170.

24. Titton RL, Gervais DA, Boland GW, Maher MM, Mueller PR. Sonography and sonographically guided fine-needle aspiration biopsy of the thyroid gland: indications and techniques, pearls and pitfalls. AJR Am J Roentgenol 2003;181:267-271.

25. Oertel YC. Fine-needle aspiration of the thyroid: technique and terminology. Endocrinol Metab Clin North Am 2007;36:737-751.

26. Lee J, Kim BK, Sul HJ, Kim JO, Lee J, Sun WY. Negative pressure is not necessary for using fine-needle aspiration biopsy to diagnose suspected thyroid nodules: a prospective randomized study. Ann Surg Treat Res 2019;96:216-222.

27. Gupta PK. Role of centrifugal force on solid-liquid two-phase flow through rotating channel. Prog Comput Fluid Dyn Int J 2017; 17:313-325. 